\title{
Malnutrition, an Important Comorbidity in Patients with Lennox Gastaut Syndrome
}

\author{
Gessen Salmerón Gómez ${ }^{1}$, Mariel Pizarro Castellanos ${ }^{2}$ and Benigno Linares Segovia ${ }^{1,3 *}$ \\ ${ }^{1}$ Department of Neuropediatrics, Hospital Materno Infantil Irapuato, México \\ ${ }^{2}$ Department of Neurology, Hospital Infantil de México Federico Gómez, México \\ ${ }^{3}$ Department of Medicine and Nutrition, University of Guanajuato, México
}

Submission: February 06, 2017; Published: March 23, 2017

*Corresponding author: Benigno Linares Segovia, Department of Medicine and Nutrition, University of Guanajuato, México, Tel: +52 477 7145859; Email: blinares70@ugtomx.onmicrosoft.com

\begin{abstract}
Background: Lennox Gastaut Syndrome (LGS) is an epileptic encephalopathy that occurs in the pediatric age is associated with cognitive impairment. It is also considered as refractory epilepsy due to its frequent resistance to antiepileptic drugs, which implies the use of multiple antiepileptic drugs for long periods of treatment, the adverse effects of which could affect the patient's nutrition.
\end{abstract}

Objective: To determine malnutrition in patients with Lennox Gastaut Syndrome and its clinical repercussion.

Methods: A retrospective cohort study was performed in patients aged 5 to 19 years with diagnosis of Lennox Gastaut Syndrome, in control of at least 5 years.Anthropometric measurements were recorded and nutritional status was determined. Demographic and clinical characteristics were recorded: type of crisis, age of diagnosis, electro encephalographic characteristics, neuro imaging, number of drugs and comorbidities.

Results: Thirty-five patients were studied, the mean age was 6 years (CI 95\%: 2-10), 55\% were men. Nutritional status was classified as normal (20\%), mild malnutrition (11.4\%) moderate malnutrition (48.5\%), severe malnutrition (17\%), and 3.1\% of the patients were overweight or obese. Alterations in the electro encephalogram were significantly more frequent in patients with malnutrition ( $\mathrm{p}=0.02)$. Patients with malnutrition required more drugs (2.8; CI 95\%:2-4) and however, the number of epileptic events was significantly higher.

Conclusion: Malnutrition is a common phenomenon in pediatric patients with Lennox-Gastaut Syndrome, and in accordance to gravity has a greater impact on crisis management by promoting refractoriness and thereby the quality of life.

Keywords: Epilepsy; Malnutrition; Lennox gastaut syndrome

Abbreviations: LGS: Lennox Gastaut syndrome; TPM: Topiramate; PTH: Phenytoin; PB: Phenobarbital; CBZ: Carbamazepine; VPA: Valproic acid; VGB: Vigabatrin; LMT: Lamotrigine; EEG: Electro Encephalo Gram

\section{Introduction}

Lennox Gastaut Syndrome (LGS) is an epileptic encephalopathy that occurs in children, so often is resistant to antiepileptic drugs with impact on quality of life of sufferers. It is accompanied by multiple comorbidities, which have a direct effect on the nutritional status: neurological diseases that conditions prostration, alteration of muscle tone, deterioration of the mechanics of swallowing, aspiration and respiratory infections [1]; The use of anti-epileptic drugs that induce enzymes, time for feeding, frequent hospitalizations, fasting periods have also been observed as risk factors.

It is known that LGS encephalopathy alone generates cognitive impairment, structural changes that affect the quality of life, this with a direct bearing on the nutritional status of patients. Malnutrition, alone, in experimental models has been shown to reduce the volume and number of cortical and glial cells, a significant break in the pyramidal cells, the reduction in the density of cortical dendritic spines and the complexity of the dendritic branches of cortex [2-7].

In patients with catastrophic epilepsies epileptic encephalopathy such as LGS, refractoriness involves the use of multiple antiepileptic drugs prolonged treatment periods, the effects of adverse impact on the nutritional status of patients, for example, Topiramate (TPM) decreases appetite; Phenytoin (PHT), Phenobarbital (PB) and Carbamazepine (CBZ) interfere 
with the metabolism of vitamin D increase the risk of osteopenia and osteoporosis [8,9]. PHT and PB decreases the absorption of vitamin B12 and folic acid [10]. Valproic acid (VPA), vigabatrin (VGB), lamotrigine (LMT) and TPM, have shown a decrease in serum total and free carnitine $[11,12]$.

In LGS encephalopathy do not have information to establish the correlation and impact of malnutrition on neurodevelopment, refractory to antiepileptic treatment, associated comorbidities and quality of life of patients suffering from it. The aim of this study is to determine the frequency of malnutrition in patients with Lennox Gastaut syndrome and its clinical repercussion.

\section{Conclusion}

We performed a retrospective cohort study in a patient aged 5 to 20 years hospitalized in the department of Neurology at the Hospital Infantil de Mexico Federico Gomez with diagnosis of Lenox Gastaut Syndrome, according to the criteria of the International League Against Epilepsy (ILAE). Demographic and clinical characteristics were recorded: type of crisis, age of diagnosis, electroencephalographic characteristics, neuroimaging, number of drugs and comorbidities. The weight, height and cephalic perimeter were measured and the body mass index was calculated.The degree of malnutrition was established by the Gomez classification for children under 5 years and Waterloo for ages 5 years 1 month to 20 years taking as reference values of the World Health Organization (WHO) in children under 5 years and the reference values of the Center for Disease Control and Prevention (CDC).

Thirty-five patients were studied, the mean age was 6 years (CI 95\%: 2-10), 55\% were men. Nutritional status was classified as normal (20\%), mild malnutrition (11.4\%) moderate malnutrition (48.5\%), severe malnutrition (17\%), and $3.1 \%$ of the patients were overweight or obese. Microcephaly was present in $62 \%$. Alterations in the electroencephalogram were significantly more frequent in patients with malnutrition $(\mathrm{p}=0.02)$. In patients without malnutrition were observed: slow spike-wave complex was observed in overall $74 \%$ more affected frontal and temporal $28 \%$, respectively, $57 \%$ right lobe predominance. In patients with malnutrition were observed: slow spike-wave complex $47 \%$, bud removal $25 \%, 24 \%$ polyspike, sharp waves $21 \%, 17 \%$ generalized dysfunction, rapid rhythms during sleep 7\%, 35\% affected temporal lobe, frontal 17\%, 60\% left dominance.

Patients with malnutrition required more drugs (2.8; CI 95\%: 2-4) and however, the number of epileptic events was significantly higher. Malnutrition is a common phenomenon in pediatric patients with Lennox-Gastaut Syndrome, and in accordance to gravity has a greater impact on crisis management by promoting refractoriness and thereby the quality of life.

\section{Acknowledgement}

The authors thank the medical and paramedical staff of the Department of Neurology of the Hospital Infantil de México Federico Gómez for the facilities to carry out this study.

\section{Declaration of conflicts of interest}

The authors report no conflicts of interest. The authors alone are responsible for the content and writing of the paper.

\section{References}

1. Bertoli S, Cardinali C, Veggiotti P, Trientani C, Testolin G, et al. (2006) Evaluation of nutritional status in children with refractory epilepsy. Nutr J 26: 5-14.

2. Bedi KS, Bhide PG (1988) Effects of environmental diversity on brain morphology. Early Hum Dev 17(1): 107-143.

3. Leuba G, Rabinowicz T (1979) Long-term effects of postnatal under nutrition and maternal malnutrition on mouse cerebral cortex. II. Evaluation of dendritic branching and spines in the visual region. Exp Brain Res 37: 299-308.

4. Morgane PJ, Kemper T, Stern W, Hawrylewicz E, Resnick O (1978) The effect of protein malnutrition on the developing central nervous system in the rat. Neurosci. Biobehav Rev 2(3): 137-230.

5. Angulo-Colmenares AG, Vaughan DW, Hinds JW (1979) Rehabilitation following early malnutrition in the rat: body weight, brain size, and cerebral cortex development. Brain Res 169(1): 121-138.

6. Cordero ME, Trejo M, Garcia E, Barros T, Colombo M (1985) Dendritic development in the neocortex of adult rats subjected to postnatal malnutrition. Early Hum Dev 12(3): 309-321.

7. Cintra L, Diaz-Cintra S, Galvan A, Kemper T, Morgane PJ (1990) Effects of protein undernutrition on the dentate gyrus in rats of three age groups. Brain Res 532(1-2): 271-277.

8. Fitzpatrick LA (2004) Pathophysiology of bone loss in patients receiving anticonvulsant therapy. Epilepsy Behav 5(Suppl2): S3-S15.

9. Hadjiloizou SM (2007): Antiepileptic drug treatmen in children. Expert Rev Neurother 7(2): 179-193.

10. Zelnick N, Isler N, Goez H, Shiffer M, David M, et al. (2008) Vigabatrin, lamotrigine, topiramate and serum carni-tine levels. Pediatr Neurol 39(1): 18-21.

11. Tan H, Orbak Z, Kantarci M, Kocak N, Karaka L (2005) Valproateinduced insulin resistance in prepubertad girls with epilepsy. J Pediatr Endocrin Metab 18(10): 985-999.

12. Dewan P, AgarwalA, Faridi MMM (2008) Effect of fhenitoin and valproic acid therapy on serum lipid levels and liverfunction test. Indian Pediatrics 45(10): 855-888. 
This work is licensed under Creative

Commons Attribution 4.0 Licens

DOI: 10.19080/OAJNN.2017.03.555602
Your next submission with Juniper Publishers will reach you the below assets

- Quality Editorial service

- Swift Peer Review

- Reprints availability

- E-prints Service

- Manuscript Podcast for convenient understanding

- Global attainment for your research

- Manuscript accessibility in different formats ( Pdf, E-pub, Full Text, Audio)

- Unceasing customer service

Track the below URL for one-step submission https://juniperpublishers.com/online-submission.php 